\title{
Influences of the adrenal gland and photoperiod on the hamster oestrous cycle
}

\author{
E. L. Bittman and I. Zucker \\ Department of Psychology, University of California, Berkeley, California 94720, U.S.A.
}

Seasonal changes in daylength are involved in the phasing of the annual gonadal cycle of the golden hamster (Reiter, 1973). Ovarian cyclicity, as manifested in regular 4-day oestrous cycles, can be maintained indefinitely by exposing hamsters to daily light periods that exceed $12.5 \mathrm{~h}$ in length (long days). When the daily light period is reduced below $12 \mathrm{~h}$ (short days), or when hamsters are blinded, oestrous cycles cease after an interval of 3-8 weeks (Sorrentino \& Reiter, 1970; Seegal \& Goldman, 1975).

This reliance on daylength to maintain or suppress gonadal activity is an example of photoperiodic time measurement and involves circadian systems (Elliott, Stetson, \& Menaker, 1972; Elliott, 1976). According to one model, long days establish appropriate phase relations in the circadian systems that regulate secretion of various hormones and thereby promote gonadal activity (internal coincidence scheme). Alternatively, the exposure of the animals to light at crucial photosensitive phases of their circadian cycles may be a prerequisite for maintenance of gonadal activity and this occurs only when days are long (external coincidence model). These models have been described by Pittendrigh (1974) and their relevance to reproductive phenomena discussed by Follett \& Davies (1975).

Adrenal hormones have been implicated in photoperiodic time measurement. In the sparrow, Zonotrichia albicollis, phase relationships between corticosterone and other hormones influence seasonal fattening, migration and reproduction (Meier, 1975) in ways consistent with either coincidence model (Follett \& Davies, 1975). In the hamster, adrenal hypofunction occurs upon exposure to short daylengths and correlates with the cessation of oestrous cyclicity (Hoffman \& Reiter, 1966). The adrenal gland secretes some of its hormones, in vivo and in vitro, with pronounced diurnal rhythmicity (Andrews \& Folk, 1964; Moore \& Eichler, 1976), and lesions of the suprachiasmatic nuclei which abolish rhythms of corticosterone secretion in rats (Moore \& Eichler, 1976), and presumably also in hamsters, prevent photoperiodically mediated gonadal regression in male hamsters (Rusak \& Morin, 1976). If gonadal function in long days depends on the adrenal, and gonadal regression in short days is mediated by adrenal hypofunction, then adrenalectomized hamsters should become acyclic in any photoperiod. The same conclusion would follow if coincidence of a particular phase of adrenal secretion with some other oscillatory event were necessary to induce gonadal cyclicity, or if adrenal hormones positioned the photosensitive phase. Alternatively, if adrenal secretions mediate the effects of short days on the neuroendocrine axis, adrenalectomy might ameliorate or abolish the suppressive effects of short days or blinding on the reproductive system. These considerations provided the rationale for the present study of adrenal participation in hamster photoperiodism.

Adult female hamsters (Mesocricetus auratus) obtained from the Lakeview Hamster Colony (Newfield, New Jersey) or bred in our laboratory from that stock were caged individually, provided with Simonsen rat pellets (maintenance diet) ad libitum, and exposed to $14 \mathrm{~h} \mathrm{light} / \mathrm{day}$. Lights were turned on at $20.00 \mathrm{~h}$ (Pacific Daylight Time) and provided approximately 129 lux of illumination at cage level. Room temperature remained relatively constant at $23^{\circ} \mathrm{C}$. Oestrous cycles were monitored by means of daily vaginal smears (Orsini, 1961) taken between 09.00 and $10.00 \mathrm{~h}$, normal cycles being characterized by a copious discharge every 4 th day.

After 3 or more consecutive 4-day oestrous cycles, hamsters were adrenalectomized and blinded (orbital enucleation) under pentobarbital-induced anaesthesia. The hamsters were offered a $0.2 \%$ $(w / v)$ sodium saccharine-1\%(w/v) sodium chloride solution to drink, a mixture which promotes 
long-term survival in most adrenalectomized hamsters (Salber \& Zucker, 1974; Snyder \& Wyman, 1951). The completeness of adrenalectomy was assessed at the end of the experiment (see Salber \& Zucker, 1974).

The criterion for establishing oestrous acyclicity was 2 weeks with no more than a single oestrous vaginal discharge. Hamsters meeting this criterion are known to have significantly reduced uterine weights, hypertrophied ovarian interstitial tissue and decreased follicular and luteal elements (Reiter, 1968): histological comparisons were not made in the present experiments. Some of the data (Table 1) are from animals that died several or more weeks after surgery. Since these deaths occurred only in adrenalectomized females they were presumed to reflect consequences of long-term uncorrected adrenal insufficiency.

Table 1. Oestrous cycles of female hamsters after blinding and adrenalectomy

\begin{tabular}{|c|c|c|}
\hline Treatment & $\begin{array}{l}\text { No. of } \\
\text { animals }\end{array}$ & $\begin{array}{l}\text { Latency to the cessation } \\
\text { of oestrous cycles (days) }\end{array}$ \\
\hline Blinding & 5 & $18,19,28,52,62$ \\
\hline \multicolumn{3}{|l|}{ Blinding \& } \\
\hline adrenalectomy & 6 & $23,32,32,42,43,45$ \\
\hline Adrenalectomy* & 3 & (cycles did not cease) \\
\hline Adrenalectomyt & 6 & $7(19), 7(20), 14(39), 17(18), 25(33), 41(54)$ \\
\hline
\end{tabular}

As shown in Table 1, oestrous cyclicity ceased within 18 to 62 days after blinding in females drinking the saccharine-saline solution (mean $=35.8$ days). This is in general agreement with the reported latencies to acyclicity of blind or short-day hamsters drinking tap water (Sorrentino \& Reiter, 1970; Seegal \& Goldman, 1975). Oestrous cycles ceased in a mean of $36 \cdot 2$ days in blinded adrenalectomized hamsters, showing that adrenalectomy did not interfere with the ability of blinding (and presumably of short days) to abolish oestrous cyclicity. After adrenalectomy only, 3 hamsters continued to show 4-day oestrous cycles for at least 9 weeks in response to the long days. Many of the adrenalectomized hamsters that died during the course of the experiment, presumably of adrenal insufficiency, exhibited several 4-day oestrous cycles (Table 1).

It therefore appears that, in the hamster, as in the rat (Feder, Brown-Grant \& Corker, 1971), adrenal hormones are not essential for the long-term expression of oestrous cyclicity. This finding and the observation that adrenalectomy does not eliminate photoperiodic regulation of the oestrous cycle suggest that adrenal hormones play no major role in an external or internal coincidence mechanism for the seasonal suspension of reproductive activity in the hamster. However, adrenal hormones may still be capable of modulating photoperiodic time measurement or ovarian regression in this species. Steroid hormones affect the period $(\tau)$ of mammalian circadian rhythms (Daan, Damassa, Pittendrigh \& Smith, 1975; Morin, Fitzgerald \& Zucker, 1977); small changes in $\tau$ may alter the phase angles with which hamsters entrain to the light : dark cycle and thus influence which photoperiods are stimulatory to the reproductive axis (Elliott, 1976; Morin, Fitzgerald, Rusak \& Zucker, 1977). It remains to be established whether adrenal hormones, especially glucocorticoids, have a physiological role in photoperiodism, for example, in determining the periodicity of the rhythm or in setting the duration and positioning of the daily photosensitive phase.

Supported in part by a Research Grant, HD-02982, from the NICHD, United States Public Health Service. E.L.B. received financial support from a National Science Foundation Fellowship. We thank Kathleen Fitzgerald for constructive criticism and Martha Kapetan for typing the manuscript. 


\section{References}

ANDrews, R.V. \& Folk, G.E. (1964) Circadian metabolic patterns in cultured hamster adrenal glands. Comp. Biochem. Physiol. 11, 393-409.

Daan, S., Damassa, D., Pittendrigh, C.S. \& Smith, E.E. (1975) An effect of castration and testosterone replacement on a circadian pacemaker in mice (Mus musculus). Proc. natn. Acad. Sci. U.S.A. 72, 3744 3747.

ElliotT, J.A., (1976) Circadian rhythms and photoperiodic time measurement in mammals. Fedn Proc. Fedn Am. Socs exp. Biol. 35, 2339-2346.

Elliott, J.A., Stetson, M.H. \& Menaker, M. (1972) Regulation of testis function in golden hamsters: a circadian clock measures photoperiodic time. Science, N.Y. 178, 771-773.

Feder, H.H., Brown-Grant, K. \& Corker, C.S. (1971) Preovulatory progesterone, the adrenal cortex and the 'critical period' for luteinizing hormone release in rats. $J$. Endocr. 50, $29-42$.

Follett, B.K. \& DAvies. D.T. (1975) Photoperiodicity and the neuroendocrine control of reproduction in birds. Symp. zool. Soc. Lond. 35, 199-224.

HoffMAN, R.A. \& ReiteR, R.J. (1966) Responses of some endocrine organs of female hamsters to pinealectomy and light. Life. Sci. 5, 1147-1151.

MeIER, A.H. (1975). Chronoendocrinology of vertebrates. In Hormonal Correlates of Behavior, pp. 469-549. Eds B. E. Eleftheriou \& R. L. Sprott. Plenum Press, New York.

Moore, R.Y. \& EICHLER, V.B. (1976) Central neural mechanisms in diurnal rhythm regulation and neuroendocrine responses to light. Psychoneuroendocrinology 1, 265-279.

Morin, L.P., FitzGerald, K.M., RuSAK, B. \& ZuCKER, I. (1977) Circadian organization and neural media- tion of hamster reproductive rhythms. Psychoneuroendocrinology 2, 73-98.

MORIN, L.P., FitzGerald, K.M. \& ZuCKer, I. (1977) Estradiol shortens the period of hamster circadian rhythms. Science, N. Y. 169, 305-307.

ORsini, M. W. (1961) The external vaginal phenomena characterizing the stages of the estrous cycle, pregnancy, pseudopregnancy, lactation and the anestrous hamster, Mesocricetus auratus Waterhouse. Proc. Anim. Care Panel 11, 193-206.

PitTendrigh, C.S. (1974) Circadian oscillations in cells and the circadian organization of multicellular systems. In The Neurosciences, Third Study Program, pp. 437-458. Eds F. O. Schmitt \& F. G. Warden. MIT Press, Cambridge, Massachusetts.

ReITER, R.J. (1968) Changes in the reproductive organs of cold-exposed and light-deprived female hamsters (Mesocricetus auratus). J. Reprod. Fert. 16, 217-222.

ReIter, R.J. (1973) Comparative physiology: pineal gland. A. Rev. Physiol. 35, 305-328.

RUSAK, B. \& MORIN, L.P. (1976) Testicular responses to photoperiod are blocked by lesions of the suprachiasmatic nuclei in golden hamsters. Biol. Reprod. 15, 366-374.

SALBER, P. \& ZUCKer, I. (1974) Absence of salt appetite in adrenalectomized and DOCA-treated hamsters. Behav. Biol. 10, 295-311.

SeEgal, R.F. \& Goldman, B.D. (1975) Effects of photoperiod on cyclicity and serum gonadotropins in the Syrian hamster. Biol. Reprod. 12, 223-231.

SNYDER, J.G. \& WYMAN, L.C. (1951) Sodium and potassium of blood and urine in adrenalectomized golden hamsters. Am. J. Physiol. 167, 328-332.

Sorrentino, S. \& ReITer, R.J. (1970) Pineal-induced alteration of estrous cycles in blinded hamsters. Gen. comp. Endocr. 15, 39-42. 